\title{
In Vitro Antimicrobial Activities of Cinnamomum Iners Leaf and Bark Extracts Against Pathogens of Food Borne Diseases
}

\author{
A Geo Vigila ${ }^{1}$, K Sahayaraj ${ }^{1 *}$ and X Baskaran ${ }^{2}$ \\ ${ }^{1}$ Department of Zoology, India \\ ${ }^{2}$ Department of Life Sciences, China \\ *Corresponding author: K Sahayaraj, Crop Protection Research Centre, Department of Zoology, St. Xavier's College, Palayamkottai, Tamil Nadu- 627 \\ 002, India
}

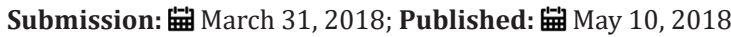

\begin{abstract}
In general, food borne diseases may arise from the consumption of contaminated food due to microbials. Cinnamomum iners Reinw. ex Blume is belongs to the family of Lauraceae which used as traditional herb to cure fever and digestive problem. In this study, we evaluated the antimicrobial

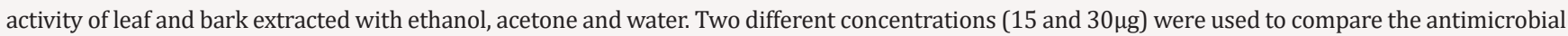
activity using in vitro disc diffusion zone. Five bacterial strains such Escherichia coli, Staphylococcus aureus, Serratia marcescens, Klebsiella pneumoniae and Pseudomonas aeroginosa and three fungal strains namely Trichophyton rubrum, Aspergillus fumigatus and Candida albicans were used. Bark extracts of C.iners exhibited higher inhibition zone against bacterial strains. Our present study concludes that bark extracts could be potential source to inhibit wide range of micro organisms than leaf extracts of C.iners.
\end{abstract}

Keywords: Antimicrobial; Cinnamomum iners; Bark extract; In vitro disc diffusion

\section{Introduction}

Plant secondary metabolites exhibit several biological applications and becoming great attention, recently [1]. People utilize enormous therapeutic medicinal plants for various human ailments and proved as novel resource of bioactive compounds as antimicrobial agent for more than centuries [2]. In general, the antimicrobial agent is a chemical or physical agent which control or even kill the microorganisms. And also, it disturbs the growth and reproduction of microorganisms such as bacteria, fungi, parasites and viruses. Of them, fungi like Aspergillus fumigatus and Candida albicans have capability to cause life-threatening systemic infections $[3,4]$. Moreover, bacteria causes following poultry diseases such as, Escherichia coli infections, salmonelloses, paratyphoid infections, fowl cholera, riemerella Anatipestifer infections, Mycoplasma, necrotic enteritis, cholangiohepatitis in broiler chickens, gangrenous dermatitis, botulism, avian tuberculosis. The fungi, Aspergillus fumigatus causes Aspergillosis (Fungal Pneumonia) in poultry while Orthomyxo virus produce Avian influenza. Several causative agents such as, Mycoplasma synoviae, Staphylococcus aureus, E.coli and certain reoviruses are causes infectious synovitis. Respiratory viruses and E. coli induce Mycoplasma gallicepticum. Aspergillosis is an acute or chronic respiratory disease, Aspergillus
Granulomatous Dermatitis as a postvaccinal complication which observed in growing broiler breeders, Aflatoxicosis, Candidiasis, Fusariotoxicoses. Omphalitis (navel infection) is characterized with reddening and tissue oedema in the umbilical region [5].

Furthermor, diarrhea associated with E. coli take place in young piglets within a few days of birth through well after weaning. Occasional cases of septicemia are attributable to E. coli [6]. Colibacillosis is a disease caused by the bacterium E. coli, which normally resides in the lower intestines of most warm blooded mammals, including dogs. It is a common disease in poultry and systemic infection occurs when large numbers of Avian Pathogenic E. Coli (APEC) gain access to the bloodstream from the respiratory tract or intestine $[7,8]$. Bacteremia progresses to septicemia and death, or the infection extends to serosal surfaces, pericardium, joints, and other organs. Infected cattle seem to be the most frequent source of infection, although buffalos, goats, sheep and camels can also pass on the bacteria [9].

Milk production is associated with agriculture for the reason that farmers nurture the live stocks in villages. Though dairying associated with agriculture, milk is consumed by only rich sector 
of people and consumption of milk is a night mare for poor section of people and hence results in undernourishment or malnutrition. India is the largest producer of milk and accounts for more than $13 \%$ of milk production [10]. Milk is an essential part of daily diet for the growing children and expectant mothers. Milk is a major constituent of the diet; its quality assurance is considered essential to the welfare of a community. Milk is nutritious food for human beings, also serves as a good medium for the growth of many microorganisms Enterococcus, Lactococcus, Streptococcus, Leuconostoc, Lactobacillus, Microbacterium, Propionibacterium, Micrococcus, coliforms, Proteus, Pseudomonas, Bacillus especially E.coli, S. tyhpi, P.aeruginosa and S.aureus [11,12].

Bacterial contamination of raw milk can originate from different sources of animals such as air, milking equipment, feed, soil, feces and grass [13]. Milk is spoiled by a wide range of microorganisms some of which are pathogenic and are responsible for milk borne diseases $[14,15]$. Not only raw milk, also pasteurized milk, concentrated milk, dried milk, cottage cheese, yoghurt, buttermilk, cream cheeses are also spoiled by microbes like bacteria and fungi. Common contaminating yeasts of cheeses include Candida spp., Kluyveromyces marxianus, Geotrichum candidum, Debaryomyces hansenii, and Pichia spp. [16]. Ternstrom et al. [17] found that five taxa of psychrotrophic Pseudomonas spp. were involved in the spoilage of raw and pasteurized milk. Brucellosis is one classical example of milk borne infection. Brucella spp being transmitted from goats to humans either through direct contact or through the milk of the infected animal. Brucella is responsible for a type of granulomatous hepatitis or an acute febrile illness in human. Tuberculosis is another disease which can be transmitted through raw milk [18]. Candida species are considered as pathogens because of their versatility and ability to survive in various anatomical sites [19]. Candida species found on normal microbiota of an individual's mucosal oral cavity, gastrointestinal tract and vagina [20], and are responsible for various clinical manifestations from mucocutaneous overgrowth to blood stream infections [21].

Cinnamomum iners is an evergreen tree belonging to the family Lauraceae. According to the Agro forestry Tree Database, C. iners is commonly found in India, Myanmar, Thailand, Malaysia, Indonesia and Southern Philippines. The major bioactive compounds of this plant are saponins, terpenes, cinnamic aldehyde and eugenol [22]. Medicinal properties of C. iners that include its antiplasmodial, cytotoxicity, amylase inhibitor, antinociceptive and anti-inflammatory, anti-diarrheal, carminative activity reported by ethnobotanical reports [23- 26]. With the synonym of wild cinnamon, the bark of this plant was used as a substitute for cinnamon in various parts of Malaysia and Thailand. Even this plant has multiple therapeutic uses, only very few reports are available [27]. The plant leaves were used to cure fever, digestive problem, headache and minor wounds [28]. The bark is used as detoxifying agent by taking as a tea [22]. In our present study, the antimicrobial activities of both leaves and bark extracts of C.iners against pathogens of food borne diseases.

\section{Materials and Methods}

\section{Collection of plant material}

Matured leaf and bark of C. iners was collected in Kumarapuram, Kanyakumari District. The voucher specimen was numbered and deposited in St.Xavier's College Herbarium (XCH), Palayamkottai. Then plant material was washed and shade dried in room temperature. The dried plant material was coarsely powdered and stored in an air tight container for extract preparation.

\section{Preparation of plant extracts}

$10 \mathrm{gms}$ of the dried powdered plant materials were soaked $(1: 6 \mathrm{w} / \mathrm{v})$ separately with $60 \mathrm{ml}$ of each of the solvents viz. acetone, ethanol and water in a soxhlet apparatus for $48 \mathrm{hr}$ (according to the boiling point of each solvents used) until complete extraction of the materials. At the end of $48 \mathrm{hr}$ each extract was filtered through What man No.1 filter paper and filtrates were concentrated at room temperature in order to reduce the volume. All the extracts were stored at $4{ }^{\circ} \mathrm{C}$ in air tight bottles for further studies.

\section{Microbial cultures}

Test bacteria: Five bacterial species were tested and collected from Microbial Type Culture Collection (MTCC), Institute of Microbial Technology, Chandigarh (Punjab), India. The bacteria include viz Gram negative Escherichia coli (MTCC 1195), Staphylococcus aureus (MTCC 96) Serratia marcescens (MTCC 8780), Klebsiella pneumoniae (MTCC 2405) and Pseudomonas aeroginosa (MTCC 424).

Test Fungi: The fungal moulds consist of Trichophyton rubrum (MTCC 296), Aspergillus fumigatus (MTCC 2550) and Candida albicans (MTCC 227) were also collected from Microbial Type Culture Collection, Institute of Microbial Technology, Chandigarh, Punjab, India.

\section{In vitro antimicrobial activities}

Disc diffusion assay as described by Rosoanaivo and Ratsmanaga-Urverg and Rabe and Van Staden [29- 31] was used for anti-bacterial activity. Sterile double distilled water and Chloramphenicol (10mg/disc) were used as positive reference control to determine the sensitivity of plant extract on each bacterial species. The antifungal activity of various extracts of Cinnamomum iners were tested by disc diffusion method [32]. The potato dextrose agar plates were inoculated with each fungal culture (10 days old) by point inoculation.

The filter paper discs (What man No. 1 diameter) impregnated with 15 and $30 \mu \mathrm{g} / \mathrm{ml}$ concentrations of the extracts were placed on test organism-seeded plates. DMSO (2\%) was used to dissolve the extracts before application on test organism-seeded plates. Nystatin $(10 \mu \mathrm{g} /$ disc $)$ used as positive control and the activity was determined after $72 \mathrm{hrs}$ of incubation at $28^{\circ} \mathrm{C}$. The diameters of the inhibition zones were measured with a caliper. All experiments were carried out in triplicate and their results are expressed as mean $\pm \mathrm{SE}(\mathrm{n}=3)$. The statistical analyses were performed by one way ANOVA with SPSS 17.0 software (Chicago, USA) and relationships were considered to be statistically significant when $\mathrm{P}<0.05$. 


\section{Result}

Table 1: Aspergillus fumigatus and Candida albicans.

\begin{tabular}{|c|c|c|c|c|c|}
\hline Samples $(\mu \mathrm{g} / \mathrm{ml})$ & $\begin{array}{l}\text { Escherichia Coli } \\
\text { (cm) }\end{array}$ & $\begin{array}{c}\text { Staphylococcus } \\
\text { Aureus (cm) }\end{array}$ & $\begin{array}{c}\text { Serratia } \\
\text { Marcescens (cm) }\end{array}$ & $\begin{array}{c}\text { Klebsiella } \\
\text { Pneumoniae }(\mathrm{cm})\end{array}$ & $\begin{array}{c}\text { Pseudomonas } \\
\text { Aeruginosa (cm) }\end{array}$ \\
\hline \multicolumn{6}{|l|}{ LEAF (cm) } \\
\hline Acetone 15 & $0.70 \pm 0.00$ & $0.93 \pm 0.06$ & - & - & - \\
\hline Acetone 30 & $0.76 \pm 0.03$ & $0.96 \pm 0.03$ & $0.73 \pm 0.03$ & - & - \\
\hline Ethanol 15 & - & - & $0.70 \pm 0.00$ & - & - \\
\hline Ethanol 30 & $0.76 \pm 0.03$ & - & $0.76 \pm 0.03$ & - & - \\
\hline Water 15 & - & - & - & - & - \\
\hline Water 30 & - & - & - & - & - \\
\hline \multicolumn{6}{|l|}{ BARK } \\
\hline Acetone 15 & $0.93 \pm 0.08$ & $0.83 \pm 0.03$ & - & $0.76 \pm 0.03$ & - \\
\hline Acetone 30 & $0.93 \pm 0.03$ & $0.83 \pm 0.03$ & $0.73 \pm 0.03$ & $0.80 \pm 0.05$ & - \\
\hline Ethanol 15 & $0.73 \pm 0.03$ & $0.70 \pm 0.00$ & - & $0.76 \pm 0.03$ & - \\
\hline Ethanol 30 & $0.86 \pm 0.03$ & $1.00 \pm 0.00$ & - & $0.83 \pm 0.03$ & - \\
\hline Water 15 & - & $0.76 \pm 0.03$ & - & - & - \\
\hline Water 30 & $0.86 \pm 0.03$ & $0.90 \pm 0.05$ & $0.76 \pm 0.03$ & $0.73 \pm 0.03$ & $0.76 \pm 0.06$ \\
\hline
\end{tabular}

In the present study, both leaf and bark extracts of C.iners were prepared in various organic solvents and screened for antibacterial

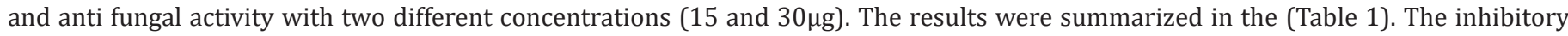
activities of the C.iners extracts were compared with the standards. Leaf acetone extract $(30 \mu \mathrm{g})$ showed maximum inhibition zone against S.aureus $(0.93 \pm 0.06 \mathrm{~cm})$ than E.coli $(0.76 \pm 0.00 \mathrm{~cm})$. On the other hand, leaf ethanol extract $(30 \mu \mathrm{g})$ showed minimum antibacterial activity $(0.76 \pm 0.03 \mathrm{~cm})$ than ethanol extract $(15 \mu \mathrm{g})$ against S.marcescens $(0.70 \pm 0.00 \mathrm{~cm})$ and E.coli $(0.76 \pm 0.03 \mathrm{~cm})$. There was no antibacterial activity shown by different leaf extracts against K.pneumoniae, Paeruginosa. No significant activity was found in leaf water extract (15 and $30 \mu \mathrm{g}$ ).

The bark acetone extract $(30 \mu \mathrm{g})$ of C.iners showed maximum inhibitory activity against E.coli $(0.93 \pm 0.03 \mathrm{~cm})$ than S. aureus $(0.83 \pm 0.03 \mathrm{~cm})$ and $S$. pneumoniae $(0.80 \pm 0.05)$. Bark ethanol extract $(30 \mu \mathrm{g})$ showed maximum inhibitory zone against S.aureus $(1.00 \pm 0.00 \mathrm{~cm})$ than E.coli $(0.86 \pm 0.03 \mathrm{~cm})$ and $\mathrm{K}$. pneumoniae $(0.83 \pm 0.03 \mathrm{~cm})$. Furthermore, bark water extract showed maximum inhibitory against S.aureus $(0.90 \pm 0.05 \mathrm{~cm})$ and minimum antibacterial activity against $K$. pneumoniae $(0.73 \pm 0.03 \mathrm{~cm})$. No effective inhibitory activity was shown against any of the tested fungal microorganisms (Trichophyton rubrum, Aspergillus fumigatus and Candida albicans).

\section{Discussion}

Plants have the capability in order to resist disease by low molecular weight compounds like secondary metabolites such as alkaloids, coumarins, isoflavonoids, polyacetylenes, quinones, tannins and terpenes which proved antimicrobial activities. Plants have unlimited capacity to synthesize aromatic secondary metabolites. Most of them are phenols or their oxygen-substituted derivatives [33]. Moreover, traditional medicine practitioners' uses

water mostly to prepare plant extracts whereas, organic solvents have been found to give more consistent antimicrobial activity when compared to water extracts [34]. In several previous studies, methanol, ethanol, and water were used frequently to prepare plant extracts for biological activities like antimicrobial activity [34-38].

Antimicrobials of plant origin have enormous therapeutic potential. There is a long history of providing the novel therapeutics from plant-derived antimicrobials [39]. The medicinal value of plants lies in some chemical substances that produce a definite physiological action on the human body and these chemical substances are called phyto chemicals and are used to cure the disease in herbal and homeopathic medicines [40]. These are nonnutritive substances and have protective or disease preventive property [41]. The most important of these bioactive compounds are alkaloids, flavonoids, tannins and phenolic compounds [42].

There arises a need and therefore to screen medicinal plants for bioactive compounds as a basis for further pharmacological studies. In previous studies, Sheng Yang et al. [43] reported that Cinnamomum osmophloeum (Lauraceae) possesses significant anti fungal activity because of Cinnamaldehyde, the major compound in the leaf. With advances in phytochemical techniques, several active principles of many medicinal plants have been isolated and introduced as valuable drug in modern systems of medicine. C.iners methanolic extracts possessed anti-microbial activity against gram positive and negative pathogenic bacteria [44]. C.zeylanicum is most sensitive in controlling the growth of B.pseudomallei, S.aureus, K. pneumoniae, and S. pneumoniae. And, it is found to be very effective against the multidrug resistant human pathogen B. pseudomallei that cause melioidosis. 
Alkaloids are reported for anti bactericidal effects in earlier studies [46-48]. Cinnamaldehyde is an aromatic aldehyde and main component of bark extract of cinnamon (Cinnamomum verum) and are proved to be active against many pathogenic bacteria $[49,50]$. The stem bark of C.tamala has antibacterial potential [51]. Leaves and barks of cinnamon have aromatic, astringent, stimulant and carminative activities [52]. In conclusion, both leaf and bark extract of C.iners studied here which provide preliminary idea that this is potentially rich in antimicrobial compounds. As per previous report [53], High Performance Liquid Chromatography (HPLC) and Gas Chromatography Mass Spectrometry (GCMS) will be carried out to screen bio-chemical constituents present in the bark and leaf extract which responsible for the antimicrobial activity in our further studies.

\section{References}

1. Baris O, Gulluce M, Sahin F, Ozer H, Kilic H, et al. (2006) Biological activities of the essential oil and methanol extract of Achillea Biebersteinii Afan. (Asteraceae). Turk J Biol 30: 65-73.

2. Das K, Tiwari RKS, Strivastava DK (2010) Techniquesfor Evaluation of medicinal plant products as antimicrobial agents: current methods and future trends. J Med Plants Res 4(2):104-111.

3. Pfaller MA, Diekema DJ (2010) Epidemiology of invasive mycoses in North America. Crit Rev Microbiol 36(1):1-53.

4. Pfaller MA, Diekema DJ (2007) Epidemiology of invasive candidiasis: a persistent public health problem. Clin Microbiol Rev 20(1):133-163.

5. Ivan D (2010) Diseases of poultry a colour atlas. (2nd edn) 5m Enterprises Inc, Chicago, USA, Pp. 60604-2900.

6. Mackinnon JD (1999) Enteritis in the young pig caused by Escherichia coli. Pig Vet J 41:227-255.

7. Straw BE, Zimmerman JJ, D’Allaire S, Taylor DJ (2013) Diseases of Swine John Wiley \& Sons, USA.

8. Bertschinger HU, Fairbrother JM (1999) Escherichia coli infections. In: BE Straw, S D'Allaire, WL Mengeling, DJ Taylor (Eds.), Diseases of swine. Iowa State University Press Ames, Iowa, USA.

9. Boukary AR, Thys E, Rigouts L, Matthys F, Berkvens D, et al. (2012) Risk factors associated with bovine tuberculosis and molecular characterization of Mycobacterium bovis strains in urban settings in Niger. Transbound Emerg Dis 59(6): 490-502.

10. Appalanaidu K, Sunitha R, Kutcharlapati, Sai Bramari G, Anitha L (2015) Isolation and Identification of Specific Pathogens, Presence of Antibiotics, Aflatoxins, Pesticide Residues and Industrial Contaminants in Supply Chain of Milk in Selected Coastal Districts of Andhra Pradesh. Advances in Bioscience and Biotechnology 6(4): 14.

11. Murinda SE, Nguyen LT, Nam HM, Almedia RA (2004) Detection of sorbitol negative and sorbitol-positive shiga toxin-producing Escherichia coli, Listeria monocytogenes, Campylobacter jejuni and Salmonella species in dairy farm environmental samples. Foodborne Pathog Dis 1(2): 97104.

12. Oliver SP, Boor KJ, Murphy SC, Murinda SE (2009) Food safety hazards associated with consumption of raw milk. Food borne Pathog Dis 6(7): 973-806.

13. Torkar KG, Teger SG (2008) The microbiological quality of raw milk after introducing the two days milk collecting system. Acta agriculturae Slovenica 92(1): 61-74.

14. Prajapati JB (1995) Fundamentals of dairy microbiology. Akta Prakashal Nadiad, Gujarat, India. 4-45.
15. Chatterjee SN, Bhattacharjee I, Chatterjee SK, Chandra G (2006) Microbiological examination of milk in Tarakeswar, India with special reference to coliforms. African Journal of Biotechnology 5(15): 1383-1385.

16. Johnson ME (2001) Cheese products. In: Marth EH, Steele JL (Eds.), Applied dairy microbiology ( $2^{\text {nd }}$ edn) New York: Marcel Dekker, USA, Pp 345-384.

17. Ternstrom A, Lindberg AM, Molin G (1993) Classification of the spoilage flora of raw and pasteurized bovine milk, with special reference to Pseudomonas and Bacillus. J Appl Bacteriol 75(1): 25-34.

18. Baths V, Roy U (2011) Mycobacterium tuberculosis using statistical coupling analysis of the esterase family proteins. J Biomed Res 25(3): 165169.

19. Calderone RA, Fonzi WA (2001) Virulence factors of Candida albicans. Trends Microbiol 9(7): 327-335.

20. Shao LC, Sheng CQ Zhang WN (2007) Recent advances in the study of antifungal lead compounds with new chemical scaffolds. Yao Xue Xue Bao 42(11): 1129-1136.

21. Eggimann P, Garbino J, Pittet D (2003) Epidemiology of Candida species infections in critically ill non-immuno suppressed patients. Lancet Infect Dis 3(11): 685-702.

22. Choi OH (2003) Tumbuhan liar. In: khasiat ubatan dan kegunaan lain $\left(1^{\text {st }}\right.$ edn). Utusan Kuala Lumpur Publications and Distributors Sdn Bhd: Kuala Lumpur, Malaysia, Pp. 132-133

23. Iida N, Ishii R, Hakamata J, Myamoto S, Oozeki H (1997) Amylase inhibitors for food and pharmaceutical. Japanese Kokai Tokkyo Koho, Japan.

24. Baruah A, Nath SC, Hazarika AK (2001) Stem bark oil of Cinnamomum iners Reinw. Indian Perfum 45: 261-263.

25. Wan OA, Ngah ZU, Zaridah MZ, Noor RA (2007) In vitro and in vivo antiplasmodial properties of some Malaysian plants used in traditional medicine. Infect Dis J Pak 16: 97-101.

26. Butkhup L, Samappito S (2011) In vitro free radical scavenging and antimicrobial activity of some selected Thai medicinal plants. Research Journal of Medicinal Plants 5(3): 254-265.

27. Annegowda HV, Gooi TS, Awang SHH, Alias NA, Mordi MN, et al. (2012) Evaluation of analgesic and antioxidant potency of various extracts of Cinnamomum iners bark. International journal of Pharmacology 8(3): 198-203.

28. Pengelly A (2004) Constituents of medicinal plants. Cambridge: CABI, p. 66.

29. Iennette EH (1985) Manual of clinical microbiology. American Association for Microbiology, Washington, DC.

30. Rosoanaivo, Ratsimanaga Urverge (1993) Biological evaluation of plants with reference to the Malagasy flora. Monograph for the IFs. Proceedings of the NAPRECA Workshop on Bio-assays, (NAPRECABA'93), Antananavivo, Madagascar. Pp. 72-79.

31. Rabe T, van Staden J (2000) Isolation of an antibacterial sesquiterpenoid from Warburgia salutaris. J Ethnopharmacol 73(1-2): 171-174

32. Taylor RS, Manandhar NP, Towers GH (1995) Screening of selected medicinal plants of Nepal for antimicrobial activities. J Ethnopharmacol 46(3):153-159.

33. Geissman TA (1963) Flavonoid compounds, tannins, lignins and related compounds. In: Florkin M, Stotz EH (eds), Pyrrole pigments, isoprenoid compounds and phenolic plant constituents, Elsevier, New York, USA, Pp. 265.

34. Parekh J, Jadeja D, Chanda S (2005) Efficacy of aqueous and methanol extracts of some medicinal plants for potential antibacterial activity. Turk J Biol 29: 203-210. 
35. Bisignino G, Sanogo R, Marino A, Aquino R, D’angelo V, et al. (2000) Antimicrobial activities of Mitracarpus scaber extract and isolated constituents. Lett Appl Microbiol 30(2): 105-108.

36. Lourens AC, Reddy D, Baser KH, Viljoen AM, Van Vuuren SF (2004) In vitro biological activity and essential oil composition of four indigenous South African Helichrysum species. J Ethnopharmacol 95(2): 253-258.

37. Salie F, Eagles PF, Leng HM (1996) Preliminary antimicrobial screening of four South African Asteraceae species. J Ethnopharmacol 52(1): 2733.

38. Rojas JJ, Ochoa VJ, Ocampo SA, Monoz JF (2006) Screening for antimicrobial activity of ten medicinal plants used in Colombian folkloric medicine: a possible alternative in treatment of non-nosocomial infections. BMC Complement Alternat Med 6: 2.

39. Silva MS, Brandao DO, Chaves TP, Filho ALF, Costa EM, et al. (2012) Study bioprospecting of medicinal plant extracts of the semiarid Northeast: Contribution to the control of oral microorganisms. Evid-Based Complent Alternat Med 2012: 681207.

40. Chitravadivu C, Manian S, Kalaichelvi K (2009) Antimicrobial studies on selected medicinal plants, Erode region,Tamilnadu, India. Middle-East Journal of Scientific Research 4(3): 147-152.

41. Ahmed F, Urooj A (2009) Glucose-lowering, hepatoprotective and hypolipidemic activities of stem bark of Ficus racemosa in streptozotocin induced diabetic rats. J Young Pharm 1(2): 160-164

42. Purkayastha S, Dahiya P (2012) Phytochemical analysis and antibacterial efficacy of babchi oil (Psoralea corylifolia) against multi-drug resistant clinical isolates. International Conference on Bioscience, Biochemistry and Bioinformatics. IPCBEE 3(1):64-68.

43. Sheng-Yang W, Pin-Fun C, Shang Tzen C (2005) Antifungal activities of essential oils and their constituents from indigenous cinnamon (Cinnamomum osmophloeum) leaves against wood decay fungi. Send to Bioresour Technol 96(7): 813-818.
44. Fazlina M, Jayant I, Sabariah I, Marina S, Mansor SM (2011) An antimicrobial compound isolated from Cinnamomum iners leaves with activity against methicillin-resistant Staphylococcus aureus. Molecules 16(4): 3037-3047.

45. Ramar P, Jayapal M, Mohammed AQ (2013) Evaluation of aromatic plants and compounds used to fight multidrug resistant infections. Evidence-Based Complem Alter Med 525613: 17.

46. Xie Q Johnson BR, Wenckus CS, Fayad MI, Wu CD (2012) Efficacy of berberine, an antimicrobial plant alkaloid, as an endodontic irrigant against a mixed- culture biofilm in an in vitro tooth model. J Endod 38(8): 1114 $-1117$

47. Kubota T, Iwai T, Takahashi Nakaguchi A, Fromont J, Gonoi T, et al. (2012) Agelasines O-U, new diterpene alkaloids with a 9-N-methyladenine unit from a marine sponge Agelas sp. Tetrahedron 68: 9738-9744.

48. Arai M, Yamano Y, Setawan A, Kobayashi M (2014) Identification of the target protein of agelasine $\mathrm{D}$, a marine sponge diterpene alkaloid, as an anti-dormant mycobacterial substance. Chembiochem 15(1): 117-123.

49. Suresh P, Ingle VK, Vijaya Lakshmi V (1992) Antibacterial activity of Eugenol in comparison with other antibiotics. J Fd Sci Technol 29: 254-256.

50. Shashidar NS (2002) Studies on bioactive natural compounds for their Antimicrobial and antioxidant properties. In: Ph. D. thesis Dept. of Microbiology, Osmania University, Hyderabad.

51. Goyal P, Chauhan A, Kaushik P (2009) Laboratory evaluation of crude extracts of Cinnamomum tamala for potential antibacterial activity. Eectronic Journal of Biology 5(4): 75-79.

52. Grover JK, Yadav S, Vats V (2002) Medicinal plants of India with antidiabetic potential. J Ethnopharmacol 81(1): 81-100.

53. Mahmudur R, Amina K, Monirul I, Nahid A, Sadia AC, et al. (2013) Evaluation of antimicrobial, cytotoxic, thrombolytic, diuretic properties and total phenolic content of Cinnamomum tamala. Int J Green Pharm 7: 3.

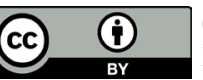

Creative Commons Attribution 4.0 International License

For possible submissions Click Here
Submit Article

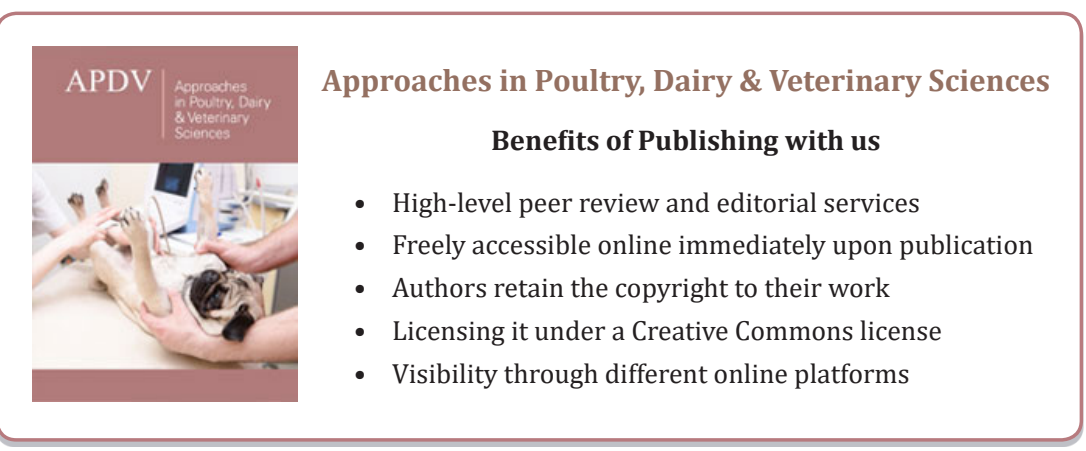

